\title{
Fuzzy Approach for Three Level Linear Programming Problems
}

\author{
Hegazy Zaher \\ Professor of Operations \\ Research Department, Institute \\ of Statistical Studies and \\ Research, Cairo University, \\ Egypt
}

\author{
Naglaa Ragaa Saeid \\ Associate Prof. of Operations \\ Research Dep., Institute of \\ Statistical Studies and \\ Research, Cairo University, \\ Egypt
}

\author{
Ahmed Serag \\ A master student, Dept. of \\ Operations Research, Institute \\ of Statistical Studies and \\ Research, Cairo University, \\ Egypt
}

\begin{abstract}
This study presents a proposed fuzzy approach for solving three level linear programming problems. This approach does not increase the complexities of original problems and usually solves a multilevel programming problem in less number of iterations. Numerical examples are used to compare the proposed approach with several approaches in the literature.
\end{abstract}

\section{Keywords}

Bi-level programming, Three-level programming, Multi-level programming, Tri-level algorithm, Fuzzy Programming

\section{INTRODUCTION}

Multilevel Optimization Problems (MLOPs) is mathematical programs (MP) which have a subset of their variables constrained to be an optimal solution of other programs parameterized by their remaining variables. It's implicitly determined by a series of optimization problems which must be solved in a predetermined sequence (Kassa et al., 2013).

Hierarchical data structures are very common in the social and behavioral sciences and Multi-level (ML) decision making models are developed for analyzing hierarchically structured data. So, multi-level programming (MLP) is an important branch of Operations Research, this problem consists of two or more levels, namely; first level, second level, and so on up to last level. MLP problem is a sequence of many optimization problems in which the constraints region of one is determined by the solution of other decision makers (DMs). The first (higher, upper) level Decision Maker (DM1) is called the leader. The lower-levels DMs (DM2, DM3 ...) called followers. They execute their policies after the decision of higher levels DMs and then the leader optimizes his objective independently but may be affected by the reaction of the followers (G. Anandalingam, 1988, Anderson 2005, O. Ben-Ayed 1993).

The simplest case of MLP problems is bi-level programming (BLP) problem. BLP is a nested optimization problem with two levels (namely the upper and lower level) in a hierarchy. It is a practical and useful tool for solving decision making problems with hierarchal structure, and has been used to solve many practical problems, such as engineering design, management, economic policy, traffic problem and so on (Zhang, 2014).

There are common characteristics of the ML organization (Ben, 1988) (Osman et al., 2013):
1) The system has interactive decision making units within a predominantly hierarchical structure.

2) The external effect on a DM's problem can be reflected in both his objective function and his set of feasible decisions.

3) The loss of cost of one level is unequal to the added gain to other level.

4) The order of the play is very important and the choice of the upper-level limits affects the choice or strategy of the lower-levels.

5) The execution of decision is sequential, from upper to lower-levels.

6) Each DM controls only a subset of the decision variables.

7) Each level optimizes its own objective function independently apart from other levels.

8) Each DM is fully informed about all prior choices

This paper article will be organized as: Section 2 provides literature review of multilevel programming problems. Section 3 provides a Fuzzy approach for solving Three Level Linear Programming Problems. Two numerical illustrative examples are presented in section 4. Section 5 provides conclusion.

\section{LITERATURE REVIEW}

Bracken and McGill (1973) are the first researchers to investigate and to define this hierarchy decision problem as a generalized MP problem. The geometric properties of the linear MLP problems are obtained in Falk (1973). In 1977, as an extension of the Stackelberg games, Candler and Norton proposed MLP models for decentralized decision-making problems. Benson, (1989) investigated the structure and properties of a linear MLP problem that may be unbounded. In 1990, Ben-Ayed and Blair showed that MLP is an NP-hard problem. The features of it, mainly its nonconvexity, make it difficult one, even when all involved functions are linear. An effective fuzzy method by using the concept of the tolerance membership function of fuzzy set theory to MLP problems is developed in Bard (1982) and is extended in Lai (1996) for satisfactory solution.

MLP problems with fuzzy approach were investigated by Lai et al, (1993) at first developed an effective fuzzy approach using the concept of tolerance membership functions for solving MLP problems. Li et al, (1994) proposed ML Dynamic Programming for General Multiple LinearQuadratic Control in Discrete-Time Systems. White, (1995) 
presented MLP, Rational Reaction Sets, and Efficient Solutions. Shih et al, (1996) used the concepts of tolerance membership functions and multiple objective optimizations to develop a fuzzy approach for solving the MLP problems. Sakawa et al, (1998) presented interactive fuzzy programming for ML linear programming problems. Shih et al, (2000) further extended Lai's concept by introducing the compensatory fuzzy operator for solving MLP problems. Shih et al, (2002) proposed a total solution of an interactive approach for integrated ML systems or MLP problems in a fuzzy environment. Sinha, (2003a, b) studied alternative MLP techniques based on fuzzy mathematical programming (FMP). A neural network approach to Multiobjective and MLP problems was presented by Hsu et al, (2004). Osman et al, 2004 presented a multi-level nonlinear multi-objective decision making under fuzziness, a new evolutionary approach for solving the ML Uncapacitated facility location problem was presented by Mari's, (2010). Baky, (2010) presented two new algorithms to solve multi-level multiobjective linear programming (ML-MOLP) problems through the fuzzy goal programming (FGP) approach. Lachhwani, et al, (2012) proposed method for solving ML fractional programming problems in a large hierarchical decentralized organization using FGP approach. A Compromise Weighted Solution for ML Linear Programming Problems was presented by Osman et al., (2013), where a non-dominated solution set was obtained.

\subsection{Three Level Linear Programming (Tllp) Formulations}

The TLLP problem can be defined as a three person, nonzero sum game with perfect information in which players move sequentially from top to bottom level. The general form of the TLLP problem can be written as [G. Anandalingam and T.L. Friesz, 1992]:

Upper level $\max _{x_{1}} f_{1}\left(x_{1}, x_{2}, x_{3}\right)=c_{11} x_{1}+c_{12} x_{2}+c_{13} x_{3}$

where $\mathrm{x}_{2}$ solves :

Middel level $\quad \max _{\mathrm{x}_{2}} f_{2}\left(x_{1}, x_{2}, x_{3}\right)=c_{21} x_{1}+c_{22} x_{2}+c_{23} x_{3}$

Bottom level $\quad \max _{x_{3}} f_{3}\left(x_{1}, x_{2}, x_{3}\right)=c_{31} x_{1}+c_{32} x_{2}+c_{33} x_{3}$

subject to:

$$
\begin{aligned}
\left(x_{1}, x_{2}, x_{3}\right) \in X= & \left\{\left(x_{1}, x_{2}, x_{3}\right) \mid A_{1} x_{1}+A_{2} x_{2}\right. \\
& \left.+A_{3} x_{3} \leq b \text { and } x_{1}, x_{2}, x_{3} \geq 0\right\} .
\end{aligned}
$$

Where $x_{i}, i=1,2,3$ is an $n_{i}$-dimensional decision variable, $c_{i 1}$, $\mathrm{i}=1,2,3$ is an $\mathrm{n}_{1}$-dimensional constant row vector, $\mathrm{c}_{\mathrm{i} 2}, \mathrm{i}=1,2$, 3 is an $n_{2}$-dimensional constant row vector, $c_{i 3}, i=1,2,3$ is an $\mathrm{n}_{3}$-dimensional constant row vector. Where $\mathrm{x}_{1}, \mathrm{x}_{2}, \mathrm{x}_{3}$ are called the top-level, middle level and bottom-level decision variables, $f_{1}, f_{2}, f_{3}$ are called the top-level, middle-level and bottom-level objective functions, respectively. Where $b$ is an m-dimensional constant vector, $\mathrm{A}_{1}, \mathrm{~A}_{2}$ and $\mathrm{A}_{3}$ are $\mathrm{m} \times \mathrm{n}_{1}, \mathrm{~m} \times \mathrm{n}_{2}$ and $m \times n_{3}$ matrices, respectively. $p_{1}, p_{2}$ and $p_{3}$ are the top-level model, middle-level model and bottom-level model, respectively. Where, $\mathrm{X}$ represents the set of the original constraints.

\section{Three level linear programming problems are mathematical optimization problems where:}

1 The set of all variables are partitioned among three vectors $\mathrm{x}_{1}, \mathrm{x}_{2}$ and $\mathrm{x}_{3}$.

2 The DM1 who has control over $\mathrm{x}_{1}$, makes a decision first, hence $\mathrm{x}_{1}$ is fixed before the second DM2 and the third DM3 select $\mathrm{x}_{2}, \mathrm{x}_{3}$ respectively.

3 After that the second level and the third level are solved as a BLP problem.

4 The DM2 who has control over $\mathrm{x}_{2}$, makes a decision first, hence $\mathrm{x}_{2}$ is fixed before the DM3 selects $\mathrm{x}_{3}$.

5 And $\mathrm{x}_{3}$ to be chosen as an optimal solution of the third level (bottom level) linear programming problem parameterized in $\mathrm{x}_{1}$ and $\mathrm{x}_{2}$.

6 After finding the optimal value $x_{3}$ of the lower level linear programming problem which is parameterized in $x_{1}$ and $x_{2}$. Then $x_{2}$ is to be chosen as an optimal solution of the second level linear programming problem parameterized in $\mathrm{x}_{1}$ and $\mathrm{x}_{2}$ is constrained by an optimal solution $\mathrm{x}_{3}$ of the lower level.

7 Finally $\mathrm{x}_{1}$ is chosen as an optimal solution of the first level (higher level) linear programming problem and $x_{1}$ is constrained by optimal solutions $\mathrm{x}_{2}$ and $\mathrm{x}_{3}$ of the second and the third level problems as given values.

\section{THE FUZZY APPROACH FOR MULTILEVEL LINEAR PROGRAMMING PROBLEMS}

It is natural that DMs have fuzzy goals for their objective functions when they take fuzziness of human judgments into consideration. For each of the objective functions $z_{i}(x), i=$ $1 \ldots \mathrm{t}$, of (3.1), assume that the DMs have fuzzy goals such as "the objective function $\mathrm{z}_{\mathrm{i}}(\mathrm{x})$ should be substantially less than or equal to some value pi.(R. E., Bellman and L. A., Zadeh 1970)

The individual minimum

$$
\mathrm{z}_{\mathrm{i}}^{\min }=\min _{x \in X} z(x), \quad \mathrm{i}=1 \ldots \mathrm{t} .
$$

The individual maximum

$$
\mathrm{z}_{\mathrm{i}}^{\max }=\max _{x \in X} z(x), \quad \mathrm{i}=1 \ldots \mathrm{t} .
$$

Of the objective functions are referred to when the DMs elicit membership functions prescribing the fuzzy goals for the objective functions $z_{i}(x), i=1$..t. The DMs determine the membership functions $\mu_{\mathrm{i}}\left(\mathrm{z}_{\mathrm{i}}(\mathrm{x})\right)$, consulting the variation ratio of degree of satisfaction in the interval between the individual minimum (3.1) and the individual maximum (3.2). The domain of the membership function is the interval $\left[\mathrm{z}_{\mathrm{i}}^{\mathrm{min}}\right.$, $\left.z_{i}{ }^{\max }\right], i=1 \ldots t$. and the DM specifies the value $z_{i}^{0}$ of the objective function for which the degree of satisfaction is 0 and the value $z_{i}^{1}$ of the objective function for which the degree of satisfaction is 1 . For the value undesired (smaller) than $z_{i}{ }^{0}$, it is defined that $\mu_{\mathrm{i}}\left(\mathrm{z}_{\mathrm{i}}(\mathrm{x})\right)=0$, and for the value desired (larger) than $\mathrm{z}_{\mathrm{i}}{ }^{1}$, it is defined that $\mu_{\mathrm{i}}\left(\mathrm{z}_{\mathrm{i}}(\mathrm{x})\right)=1$. 
For the sake of simplicity, a linear membership function is adopted, which characterizes the fuzzy goal of the DM at each level. The corresponding linear membership function $\mu_{\mathrm{i}}\left(\mathrm{z}_{\mathrm{i}}\right)$ is defined as:

$\mu_{i}\left(z_{i}(x)\right)= \begin{cases}0, & \mathrm{z}_{\mathrm{i}}(\mathrm{x})>z_{i}^{0} \\ \frac{z_{i}(x)-z_{i}^{0}}{z_{i}^{1}-z_{i}^{0}}, & \mathrm{z}_{\mathrm{i}}^{1}<\mathrm{z}_{\mathrm{i}}(\mathrm{x}) \leq z_{i}^{0}, \\ 1, & \mathrm{z}_{\mathrm{i}}(\mathrm{x}) \leq z_{i}^{1}\end{cases}$

Where $\mathrm{z}_{\mathrm{i}}^{0}$ and $\mathrm{z}_{\mathrm{i}}{ }^{1}$ denote the value of the objective function $\mathrm{z}_{\mathrm{i}}(\mathrm{x})$ such that the degree of membership function is 0 and 1 , respectively, and it is assumed that the DMs subjectively assess $z_{i}^{0}$ and $z_{i}^{1}$. When the problem is maximization

$$
\mathrm{z}_{\mathrm{i}}^{\mathrm{min}}=\mathrm{z}_{\mathrm{i}}^{0} \quad \text { and } \mathrm{z}_{\mathrm{i}}^{\text {max }}=\mathrm{z}_{\mathrm{i}}^{1}
$$

When the problem is minimization

$$
\mathrm{z}_{\mathrm{i}}^{\max }=\mathrm{z}_{\mathrm{i}}^{0} \quad \text { and } \quad \mathrm{z}_{\mathrm{i}}^{\mathrm{min}}=\mathrm{z}_{\mathrm{i}}{ }^{1}
$$

The DM1 determines the minimal satisfactory and by introducing an auxiliary variable $\lambda$, Problem (2.1) can be transformed into the following linear programming model:

$\max$ imize $\lambda$

$x, \lambda$

subject to

$$
\begin{aligned}
& \mathrm{A}_{1} x_{1}+\ldots+A_{t} x_{t} \leq b, \\
& \mu_{1}\left(z_{1}(x)\right) \geq \lambda, \\
& \mu_{2}\left(z_{2}(x)\right) \geq \lambda, \\
& \mu_{3}\left(z_{3}(x)\right) \geq \lambda, \\
& \mu_{1}\left(z_{1}(x)\right) \geq \mu_{2}\left(z_{2}(x)\right) \\
& \mu_{2}\left(z_{2}(x)\right) \geq \mu_{3}\left(z_{3}(x)\right) \\
& \lambda \in[0,1] \\
& \mathrm{x} \geq 0
\end{aligned}
$$

And $\lambda=\min \left(\mu_{1}\left(z_{1}(x), \ldots, \mu_{t}\left(z_{t}(x)\right)\right.\right.$

After DM1 determines the minimal satisfactory $=\delta$, and the constraints described in (3.4), the following problem will be formulated:

$\underset{x, \lambda}{\max } \operatorname{imize} \lambda$

subject to

$$
\begin{aligned}
& \mathrm{A}_{1} x_{1}+\ldots+A_{t} x_{t} \leq b, \\
& \mu_{1}\left(z_{1}(x)\right) \geq \delta, \\
& \mu_{2}\left(z_{2}(x)\right) \geq \lambda, \\
& \mu_{3}\left(z_{3}(x)\right) \geq \lambda, \\
& \lambda \in[0,1] \\
& \mathrm{x} \geq 0
\end{aligned}
$$

\subsection{The proposed Approach procedure}

This procedure shows the steps of the proposed fuzzy approach for dealing with the TLLP problems.

\section{Step 1:}

Each DM in all levels firstly solves his problem independently with respect to the set of all constraints, if the solution is reached, stop. Otherwise go to step two.

\section{Step 2:}

Build the membership functions of all the DMs objective functions according to them tolerances as in (3.3).

Step 3:

The DM1 determines the minimal satisfactory and by introducing an auxiliary variable, Problem (2.1) can be transformed into the linear programming model (3.4).

Step 4:

After DM1 determines the minimal satisfactory $=\delta$, and the constraints described in (3.4), the problem will be formulated as in (3.6) and solve model (3.6) by simplex method.

\section{Stop.}

This proposed approach reduces the number of iterations

\section{ILLUSTRATIVE EXAMPLES}

Example 1: Consider the following numerical TLLP problem (Shih, H.S. 1996)

$$
\max _{x_{1}} f_{1}=7 x_{1}+3 x_{2}-4 x_{3} \quad\left(1^{\text {st }} \text { level }\right)
$$

where $\mathrm{x}_{2}, x_{3}$ solve:

$$
\begin{array}{ll}
\max _{\mathrm{x}_{2}} f_{2}=x_{2} & \left(2^{\text {nd }} \text { level }\right) \\
\text { where } \mathrm{x}_{3} \text { solve: } & \\
\quad \max _{3}=x_{3} & \left(3^{\text {rd }} \text { level }\right)
\end{array}
$$

subjet to :

$$
\begin{array}{r}
x_{1}+x_{2}+x_{3} \leq 3 \\
x_{1}+x_{2}-x_{3} \leq 1 \\
x_{1}+x_{2}+x_{3} \geq 1 \\
-x_{1}+x_{2}+x_{3} \leq 1 \\
x_{3} \leq 0.5 \\
x_{1}, \quad x_{2}, \quad x_{3} \geq 0
\end{array}
$$

Data of the final iteration including an optimal solution to problem (4.1) are shown in Table 4.1.

Table 4.1: example 1 results using the proposed approach and other different approaches:

\begin{tabular}{|c|c|c|c|}
\hline & $\begin{array}{l}\text { the proposed } \\
\text { approach Fuzzy } \\
\text { approach) }\end{array}$ & $\begin{array}{l}\text { Osman M. S et } \\
\text { al., 2013 (Non } \\
\text { Fuzzy } \\
\text { approach) }\end{array}$ & $\begin{array}{l}\text { Sakawa et al., } \\
1998 \text { (Fuzzy } \\
\text { approach) }\end{array}$ \\
\hline$x_{1}^{1}$ & 0.98 & 1 & 0.845 \\
\hline$x_{2}^{1}$ & 0.52 & 0.5 & 0.65 \\
\hline$x_{3}^{1}$ & 0.50 & 0.5 & 1.0 \\
\hline
\end{tabular}




\begin{tabular}{|c|c|c|c|}
\hline$\mu_{1}^{1}$ & 0.75 & 0.75 & 0.69 \\
\hline$\mu_{2}^{1}$ & 0.52 & 0.5 & 0.65 \\
\hline$\mu_{3}^{1}$ & 1 & 1 & 1.0 \\
\hline
\end{tabular}

From the numerical results in table 4.1, the result of the proposed approach nears the result of $\mathrm{K}^{\text {th }}$ best algorithm.

Example 2: Consider the following numerical TLLP problem (Shih, H.S. 1996)

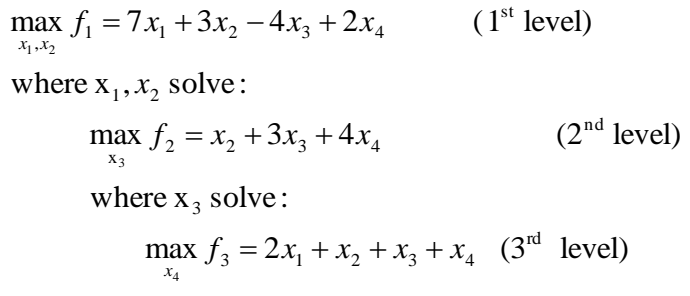

subjet to:

$$
\begin{aligned}
& x_{1}+x_{2}+x_{3}+x_{4} \leq 5 \\
& x_{1}+x_{2}-x_{3}-x_{4} \leq 2 \\
& x_{1}+x_{2}+x_{3} \geq 1 \\
& -x_{1}+x_{2}+x_{3} \leq 1 \\
& x_{1}-x_{2}+x_{3}+2 x_{4} \leq 4 \\
& x_{1}+2 x_{3}+3 x_{4} \leq 3 \\
& \quad x_{4} \leq 2 \\
& x_{1}, \quad x_{2}, \quad x_{3}, x_{4} \geq 0
\end{aligned}
$$

Data of the final iteration including an optimal solution to problem (4.2) are shown in Table 4.2.

$\mathrm{X}_{1}=1.27, \mathrm{X}_{2}=1.31, \mathrm{X}_{3}=0, \mathrm{X}_{4}=0.58$

Table 4.2: example 2 results using the proposed approach and other different approaches

\begin{tabular}{|c|c|c|c|}
\hline \multicolumn{5}{|c|}{$\begin{array}{l}\text { The proposed } \\
\text { Approach } \\
\text { (Fuzzy } \\
\text { approach) }\end{array}$} & $\begin{array}{l}\text { Osman M. S et } \\
\text { al 2013 (Non } \\
\text { Fuzzy } \\
\text { approach) }\end{array}$ & $\begin{array}{l}\text { Sinha 2003b } \\
\text { (Fuzzy } \\
\text { approach) }\end{array}$ \\
\hline $\mathrm{F}_{1}$ & 13.98 & 16.25 & 12.01 \\
\hline $\mathrm{F}_{2}$ & 3.63 & 1 & 3.18 \\
\hline $\mathrm{F}_{3}$ & 4.43 & 4.75 & 4.94 \\
\hline$\mu_{1}^{1}$ & 0.85 & 0.80 & 0.72 \\
\hline$\mu_{2}^{1}$ & 0.54 & 0.20 & 0.39 \\
\hline$\mu_{3}^{1}$ & 0.86 & 0.937 & 0.96 \\
\hline
\end{tabular}

From the numerical results in table 4.2 , the result of the proposed approach nears the result of $\mathrm{K}^{\text {th }}$ best algorithm.



Figure 1: comparison membership

\begin{tabular}{|c|c|c|}
\hline Example & $\begin{array}{l}\text { Number of iteration in } \\
\text { this paper }\end{array}$ & $\begin{array}{l}\text { Number of } \\
\text { iteration in } \\
\text { the } \mathrm{K}^{\text {th }} \text {-best } \\
\text { algorithm }\end{array}$ \\
\hline $\begin{array}{l}\text { Example } 1 \\
\text { (Shih, H.S. 1996) }\end{array}$ & 1 & 3 \\
\hline $\begin{array}{l}\text { Example } 2 \\
\text { (Shih, H.S. 1996) }\end{array}$ & 1 & 3 \\
\hline
\end{tabular}

Figure 1 explains the comparison membership functions and the value of functions. The first and the third membership functions of three approaches are near, but the second membership function of the proposed approach is the biggest value.

Table 4.3: The comparison iteration of the purpose approach with the Kth-best algorithm

From table 4.3, the purpose approach has iteration less than the $\mathrm{K}^{\text {th }}$-best algorithm.

\section{CONCLUSION}

This study designs approach for solving TLPP. The numerical results show that approach is feasible and efficient. This approach does not increase the complexities of original problems and it usually solves a multilevel programming problem in a single iteration. The result of the proposed approach nears the result of $\mathrm{K}^{\text {th }}$ best algorithm. It can be extended this idea to solve multi-level linear programming and multi-level multi-objective linear programming.

\section{REFERENCES}

[1] A. Baky, Solving multi-level multi-objective linear programming problems through fuzzy goal programming approach, Applied Mathematical Modeling, 34 (2010) 2377-2387.

[2] H. P. Benson, On the Structure and Properties of a Linear Multilevel Programming Problem, Journal of 
Optimization Theory and Applications, 60 (1989) 353373.

[3] J. Bracken and J.M. McGill, Mathematical programs with optimization problems in the constraints Operations Research, 21 (1973) 37-44.

[4] W. Candler and R. D. Norton, Multilevel Programming and Development Policy, World Bank Staff, Working Paper 258, (1977) Washington, DC.

[5] E. Anderson and N. Joglekar, A Hierarchical Product Development Planning Framework, Production and Operations Management, 14 (3) (2005)344-361.

[6] E.S. Lee and H.S. Shih, Fuzzy and Multi-Level Decision Making, 1st edition, London: Springer, 2001, Chapters 1,

[7] G. Anandalingam, A Mathematical Programming Model of Decentralized Multi- Level Systems, Journal of Operational Research Society, 39 (11) (1988) 10211033.

[8] G. Anandalingam and T.L. Friesz, Hierarchical Optimization: an Introduction, Annals of Operations Research, 34 (1) (1992) 1-11.

[9] S. S. HSU, et al., A Neural Network Approach to Multiobjective and Multilevel Programming Problems, Computers and Mathematics with Applications, 48(2004) 95-108.

[10] J. F. Bard and J. E. Falk, an Explicit Solution to the Multi-Level Programming Problems, Computers and Operations Research, 9 (1982) 77-100.

[11] J. Falk, A Linear Max-Min Problem, Mathematical Programming, 5 (1973) 169-181.

A. M. Kassa, et al., A multi-parametric programming algorithm for special classes of non-convex multilevel optimization problems. An International Journal of Optimization and Control: Theories \& Applications, 3(2) (2013)133-144.

[12] K. Lachhwani, et al., Mathematical solution of multilevel fractional programming problem with fuzzy goal programming approach, 2012.

[13] D. LI, et al., Multilevel Dynamic Programming for General Multiple Linear-Quadratic Controls in DiscreteTime Systems, Computers Math. Applic, 27 (1994) 5966.

[14] M.S. Osman, et al., A multi-level Nonlinear MultiObjective Decision Making under Fuzziness, J. Appl. Math. Comp., 153 (2004) 239-252.
[15] M.S. Osman, et al., A Compromise Weighted Solution for Multilevel Linear Programming Problems, Journal of Engineering Research and Applications, 3 (2013) 927936.

[16] M. Mari'c, An efficient Genetic Algorithm for Solving the multi-Level Uncapacitated Facility Location Problem, Computing and Informatics, 29 (2010) 183201.

[17] O. Ben-Ayed and C.E. Blair, Computational Difficulties of Bi-level Linear Programming, Operations Research, 38(1988) 556-560.

[18] O. Ben-Ayed, Bi-Level Linear Programming, Computers and Operations Research, 20 (1993) 485-501.

[19] R. E. Bellman and L.A. Zadeh, Decision-Making in a Fuzzy Environment, Manage. Sci., 17 (1970) 141-164.

[20] M. Sakawa, et al., Interactive Fuzzy Programming for Multilevel Linear Programming Problems, Computers Math. Applic, 36 (1998) 71-86.

[21] H.S. Shih, et al., Fuzzy Approach for Multi-Level Programming Problems, Computers and Operations Research, 23 (1) (1996) 73-91.

[22] H.S. Shih and E.S. Lee, Compensatory Fuzzy Multiple Level Decision Making, Fuzzy Sets and Systems, 14 (2000) 71-87.

[23] H.S. Shih, et al., An Interactive Approach for Integrated Multilevel Systems in a Fuzzy Environment, Mathematical and Computer Modeling, 36 (2002) 569585 .

[24] S. Sinha, Fuzzy Mathematical Programming Applied to Multi-Level Programming Problems, Computers and Operations Research, 30 (2003) a 1259-1268.

[25] S. Sinha, Fuzzy Programming Approach to Multi-Level Programming Problems, Fuzzy Sets and Systems, 136 (2003) b 189-202.

[26] D. J. White, Multilevel Programming, Rational Reaction Sets, and Efficient Solutions, Journal of Optimization Theory and Applications, 87 (1995) 727-746.

[27] Y.J. Lai, Hierarchical Optimization: a Satisfactory Solution, Fuzzy Sets and Systems, 77(1996) 321-335.

[28] L. Zhang, A Fuzzy Algorithm for Solving a Class of BiLevel Linear Programming Problem, Appl. Math. Inf. Sci., 8, (2014) 1823-1828. 